\title{
NEPHTYIDAE (ANNELIDA; POLYCHAETA) DO LITORAL DO ESTADO DO PARANĀ (BRASIL)
}

\author{
Paulo da Cunha Lana* \\ Centro de Biologia Marinha \\ Universidade Federal do Paraná \\ 83200 - Pontal do Sul - Paraná
}

Palavras-chave: Nephtyidae; taxonomia; Brasil

Título abreviado: Nephtyidae do Paraná

\section{ABSTRACT}

Nephtyidae (Annelida; Polychaeta) from the Paraná coast (Brazil)

The Nephtyidae from the Paraná coast (SE Brazil) are represented by 7 species in 3 genera, namely Nephtys acrochaeta, $N$. squamosa, $N$. fluviatilis, $N$. simoni, Inermonephtys palpata, Aglaophamus juvenalis and Aglaophamus uruguayi. Inermonephtys palpata, previously known from Australia, is recorded for the first time in Atlantic waters. Nephtys simoni is also a new record to the Brazilian coast. A key and descriptions, besides some comments on geographical distribution, are provided for all species examined.

\section{INTRODUÇÃO}

Referências a Nephtyidae da costa brasileira foram feitas por Kinberg (1866), Hartman $(1949,1950,1953)$, Nonato \& Luna (1970), Orensanz \& Gianuca (1974), Fauchald (1976), Amaral (1977), Rullier \& Amoureux (1979), Lana (1981), Nonato (1981) e Temperini (1981). Onze espécies eram conhecidas até o momento, a saber, Nephtys laciniosa Grube, 1881, Nephtys acrochaeta Hartman, 1950, Nephtys caeca (Fabricius, 1780), Nephtys fluviatilis Monro, 1937, Nephtys hombergi Savigny, 1818, Nephtys magellanica Augener, 1912, Nephtys squamosa Ehlers, 1887, Aglaophamus macroura (Schmarda, 1861), Aglaophamus uruguayi Hartman, 1953, Aglaophamus juvenalis (Kinberg, 1866) e Aglaophamus dibranchis (Grube, 1877).

Nephtys laciniosa é conhecida apenas da descrição original e foi considerada indeterminável por Hartman (1950). Nephtys caeca e N. hombergi foram listadas por Nonato (1981), sem descrições ou registros de ocorrência. As referências a Nephtys magellanica e Aglaophamus dibranchis (Fauchald, 1976; Lana, 1981; Nonato, 1981; Temperini, 1981) são aqui consideradas duvidosas e discutidas a seguir.

0 presente trabalho trata de espécies obtidas no decorrer de um levantamento dos poliquetas errantes do litoral do Estado do Paraná, entre os anos de 1981 e 1984, nos ambientes estuarinos de Paranaguá e Guaratuba, nas praias arenosas de mar aberto e na plataforma continental adjacente, até as proximidades do talude. A coleção encontra-se integralmente depositada no Centro de Biologia Marinha, Universidade Federal do Paraná, Pontal do Sul, Paraná, sob os números MCBM BPO-01 a MCBM-BPO-34.

\footnotetext{
* Professor Adjunto III do Centro de Biologia Marinha (UFPR)
} 


\section{LISTA DAS ESTAÇÕES DE COLETA}

Ba ías de Paranaguá e Laranjeiras, Coletor: Paulo da Cunha Lana. Aparelho: Pegador do tipo Van Veen, modificado, de $0,05 \mathrm{~m}^{2}$.

A-5 - 07/11/1981 - Barra sudeste, próximo ao canal da Galheta. 13 metros, areia fina.

D-7 - 28/05/1982 - Canal de Paranaguá, Boia 14.12 metros, areia lodosa com conchas.

D-8 - 28/05/1982 - Canal de Paranaguá, Boia 10, 18 metros, areia média com conchas.

D-9 - 28/05/1982 - Ponta do Poço, Pontal do Sul. 10 metros, lodo com restos -vegetais.

F-3 - 16/12/1983 - Baía das Laranjeiras, próximo à Ponta da Coroazinha, Itha do Mel. 6 metros, areia com lodo.

F-9 - 16/12/1983 - Baía das Laranjeiras, próximo às ilhas Bananas. 10 metros, areia com silte-argila.

MG-1 - 16/12/1983 - Manguezal da ilha Talhada, Baía de Paranaguá. Entre-marés, substrato siltico-argiloso.

PR-1 - 16/04/1984 - Gamboa Perequê, Pontal do Sul. 1 metro, areia fina bem selecionada e areia com silte-argila.

Praia de Pontal do Sul. Coletor: Paulo da Cunha Lana.

PS-1 - 07/08/1982 - Região entre-marés, areia fina selecionada.

PS-2 - 01/12/1983 - Região entre-marés, areia fina selecionada.

Baía de Guaratuba, Coletores: Ana Cláudia Muller e Iago Ferreira Leite. Aparelho: Pegador do tipo Van Veen, modificado.

GR-2 - 18/01/1984 - Norte da ilha da Pescaria. 5 metros, areia com silte-argila e restos vegetais.

MG-3 - 30/01/1984 - Manguezal da foz do rio do Cedro. Região entre-marés, areia com silte.

Plataforma continental. Operações SUESTE I e SUESTE II (convênio DHN-CBM/ UFPr). N. Oc. "Almirante Saldanha". Aparelhos: Pegador do tipo Van Veen, modificado, e draga retangular.

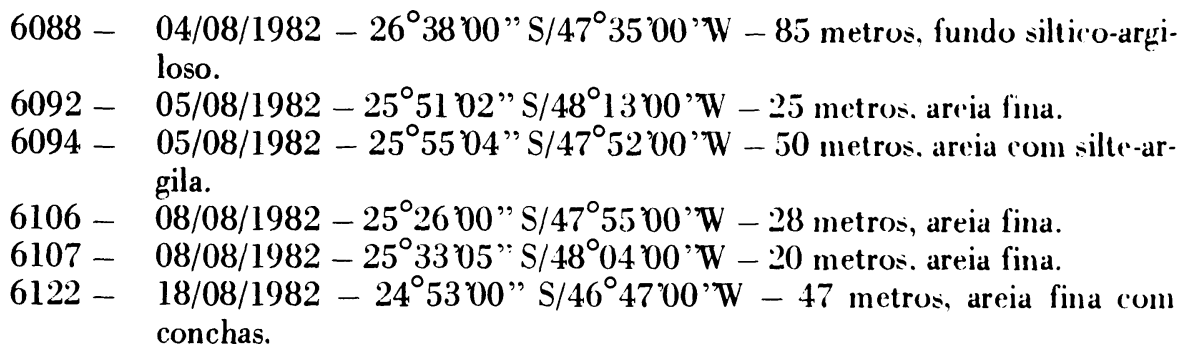


$6127-18 / 08 / 1982-24^{\circ} 44^{\prime} 03^{\prime \prime} \mathrm{S} / 45^{\circ} 55^{\prime} 00^{\prime} \mathrm{W}-68$ metros, areia com silte-argila.

$6138-21 / 08 / 1982-24^{\circ} 24.05^{\prime \prime} \mathrm{S} / 43^{\circ} 3400^{\prime} \mathrm{W}-60$ metros, areia com silte-argila.

6244 - $17 / 05 / 1983-25^{\circ} 57^{\prime} 00^{\prime \prime} \mathrm{S} / 47^{\circ} 49^{\prime} 00^{\prime} \mathrm{W}-50$ metros, areia com silte-argila.

6254 - 20/05/1983 - $25^{\circ} 50^{\prime} 00^{\prime \prime} \mathrm{S} / 47^{\circ} 0900^{\prime} \mathrm{W}-71$ metros, silte-argila.

6255 - 25/05/1983 - $25^{\circ} 38^{\circ} 00^{\prime \prime} \mathrm{S} / 47^{\circ} 31^{\prime} 00^{\prime} \mathrm{W}-53$ metros, areia com silteargila.

6256 - 25/05/1983 - $25^{\circ} 2600^{\prime \prime} \mathrm{S} / 47^{\circ} 55^{\circ} 00^{\prime} \mathrm{W}-25$ metros, areia fina.

6287 - 01/06/1983 - $24^{\circ} 3604^{\prime \prime}$ " $S / 45^{\circ} 12^{\prime} 00^{\prime} \mathrm{W}$ - 88 metros, areia com silte-argila e conchas.

6288 - $01 / 06 / 1983-24^{\circ} 24,00^{\prime \prime} \mathrm{S} / 45^{\circ} 34,00^{\prime} \mathrm{W}-60$ metros, silte-argila.

\section{CHAVE PARA AS ESPÉCIES DE NEPHTYIDAE DO LITORAL DO PARANÁ}

A chave a seguir foi preparada especificamente para as formas coletadas ao. longo do litoral paranaense e na plataforma adjacente. Deve ser utilizada com cautela e as identificações confirmadas pelas descrições que se seguem e pelas ilustrações em anexo.

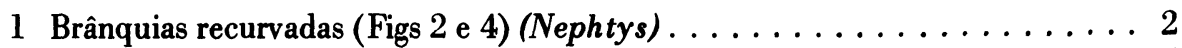
Brânquias involutas (Figs 16 e 17) (Aglaophamus) ............ 5

2 Lamelas ou expansões dorsais bem desenvolvidas, à semelhança de escamas, principalmente em parapódios medianos e posteriores (Figs 2 e 5 ) . . . . . . 3 Lamelas dorsais à semelhança de escamas ausentes . . . . . . . . . 4

3 Lobos setígeros afilados, tão ou mais longos que as lamelas neturopodiais (Fig. 2); setas pós-aciculares com esporão caracter ístico (Fig. 3) . . Nephtys acrochaeta Lobos set ígeros arredondados, muito mais curtos que as lamelas neuropodiais pós-setais foliáceas (Fig. 5); setas pós-aciculares desprovidas de esporão . . . . . . . . . . . . . . . . . . . . . . . . . . Nephtys squamosa

4 Brânquias ausentes a partir do setígero 36; prostômio com um par de ocelos puntiformes dorso-laterais; porção anterodorsal do corpo com pigmentação estriada e descontínua, evidente mesmo em exemplares fixados; restrita a ambientes de água doce ou baixa salinidade . . . . . . . . Nephtys fluviatilis Brânquias presentes até os últimos setígeros; prostômio com mancha ocelar puntiforme e avermelhada em posição dorso-mediana; ausente em ambientes de baixa salinidade . . . . . . . . . . . . . . Nephtys simoni

5 Probóscide lisa, desprovida de papilas de qualquer espécie; cirros ventrais muito mais desenvolvidos do que os lobos e lamelas neuropodiais (Figs 11-12) . . . . $\ldots \ldots \ldots \ldots \ldots \ldots \ldots \ldots$. . . . . . . . . . . . . . . . . . Probóscide com papilas terminais e sub-terminais; cirros ventrais menos desenvolvidos que os lobos e lamelas neuropodiais (Figs. 16-19) (Aglaophamus). . . . .

6 Probóscide com 16 fileiras de papilas sub-terminais; prostômio sem manchas ocelares (em material fixado); brânquias presentes a partir do setígero 4 
(Fig. 16); cirros notopodiais muito longos e filiformes em parapódios medianos, tão desenvolvidos quanto as brânquias (Fig. 17) . . . . . . . . . . . . Prosbóscide com 20 fileiras de papilas sub-terminais; prostômio com um par d!r manchas ocelares puntiformes de côr avermelhada; cirros notopodiais sempre curtos e cônicos (Figs. 18-19); brânquias reduzidas nos 8-9 setígeros anterior's. embora evidentes desde o setígero 4 (Fig. 18) . . . . . Aglaophamus uruguayi

\section{Nephtys Cuvier, 1817}

Nephtys acrochaeta Hartman, 1950

(Figs. 1-3)

Nephtys acrochaeta Hartman, 1950: 114, est. 16, figs. 1-6; Fauchald, 1976: 18. fig. 1 d-e.

Descrição - 5 exemplares examinados. A descrição se baseia num fragmento anterior com 40 setígeros, $25 \mathrm{~mm}$ de comprimento e $3 \mathrm{~mm}$ de largura. Coloração amarelada, com áreas circulares pigmentadas junto à linha mediana da porção antero-dorsal do corpo (em material fixado). Prostômio desprovido de manchas ocelares, com um par de antenas frontais e um par de órgãos nucais papiliformes muito evidentes junto à extremidade posterior do prostômio. Brânquias (ou cirros interramais) presentes a partir do setígero 11 (em um dos exemplares examinados, a partir do setígero 4). Cirros notopodiais cônicos e afilados. Primeiro par de cirros ventrais muito desenvolvidos, simulando antenas prostomiais. Lamelas notopodiais pré-setais arredondadas e mais curtas que os lobos setígeros (Fig. 1). Lamelas pós-setais muito desenvolvidas e foliáceas. Parede do corpo expandida em lâminas que simulam escamas dorsais, particularmente em parapódios medianos e posteriores (Fig. 2). Lobos setígeros afilados, com acículos retos. Setas pré-aciculares capilares, harradas. Setas pós-aciculares de dois tipos: a) lanceoladas, lisas ou tenuemente serrilhadas, em posição dorsal ou ventral; b) setas semelhantes, mas dotadas de um esporão basal (Fig. 3), situadas em posição mediana no feixe . Probóscide não dissecada (segundo Hartman, com 21 fileiras de papilas subterminais).

Ocorrência - Est. 6127 (MCBM-BPO-01, 1 exemplar); Est. 6138A (MCBM-BPO-02. 1 exemplar); Est. 6138C (MCBM-BPO-03, lex.); Est. 6287 (MCBM-BPO-04, 1 ex.): Est. 6288 (MCBM-BPO-05, 1 ex.). Em fundos areno-lodosos com conchas, na plataforma continental, entre 60 e 88 metros de profundidade.

Distribuição - Costa sudeste do Brasil (São Paulo, Rio Grande do Sul).

Discussão - Nephtys acrochaeta foi equivocadamente referida para a costa uruguaia na descrição original de Hartman (1950), como apontado por Orensanz \& Gianuca (1974). A estação 1 da Expedição Antártica Sueca de 1901-1903, de onde provém o material tipo, situa-se, na verdade, ao largo das costas rio-grandenses $\left(33^{\circ} \mathrm{S}\right.$ e $\left.51^{\circ} 10 \mathrm{~W}\right)$. Nephtys acrochaeta pode ser superficialmente confundida com Nephtys 
squamosa por apresentar expansões dorsais lamelares à semelhança de escamas. Apresenta, no entanto, lamelas podiais muito menos desenvolvidas e setas pós-aciculares dotadas de esporão característico, único entre as espécies conhecidas do gênero. Formas juvenis das duas espécies devem ser cuidadosamente analisadas para evitar identificações falhas. Incluo a espécie no presente levantamento, embora os registros citados correspondam a fundos da plataforma continental do Estado de São Paulo.

\section{Nephtys squamosa Ehlers, 1887}

(Figs. 4-5)

Nephtys squamosa Ehlers, 1887: 128, est. 37, figs. 7-10; Hartman, 1950: 110; Nonato \& Luna, 1970: 71, figs. 27-31; Fauchald, 1976: 18.

Descrição - 5 exemplares completos e vários fragmentos examinados. A descrição se baseia num fragmento anterior, com $14 \mathrm{~mm}$ de comprimento e $1,5 \mathrm{~mm}$ de largura, para 30 setígeros. 0 material fixado apresenta, em geral, coloração variando de âmbar-amarelada a avermelhada, com mancha pigmentar violácea na parte posterior do prostômio, à altura dos set ́geros $2 \mathrm{e} 3$. Margem anterior do prostômio espatula$\mathrm{da}$, com bordas translúcidas. Antenas anteriores ou frontais muito pequenas, menores que as laterais, de inserção ventro-lateral. Largüra máxima do prostômio igual à metade ou um terço da largura máxima do corpo. Brânquias presentes a partir do setígero 3 , bem desenvolvidas, ocupando praticamente todo o espaço interramal (Fig. 4). Lamelas dorsais rebatidas sobre a superfície dorso-lateral do corpo, simulando escamas, mais desenvolvidas e fortemente imbricadas nas regiões mediana $\mathrm{e}$ posterior do corpo (Fig. 5). Lamelas pré-setais pouco desenvolvidas ao longo de todo o corpo, ao contrário das pós-setais, que são foliáceas e alongadas, envolvendo a base dos feixes de setas. Setas pré-aciculares barradas e curtas. Setas pós-aciculares em fita, curtas na extremidade do feixe e longas no centro, com serrilhado tênue. Probóscide orlada por 20 pares de papilas.

Ocorrência - Est. D-9 (MCBM-BPO-06, 1 ex.); Est. 6092 (MCBM-BPO-07, 1 ex.); Est. 6106C (MCBM-BPO-08, 1 ex.); Est. 6106D (MCBM-BPO-09, 1 ex.); Est. 6107B (MCBM-BPO-10, fragmentos); Est. 6107D (MCBM-BPO-11, fragmentos); Est. 6255 (MCBM-BPO-12, 1 ex.). Em fundos arenosos e areno-lodosos na entrada das baías, e em fundos de areia fina e areno-lodosos da plataforma, entre 10 e 53 metros de profundidade.

Distribuição - Ambos os lados da América tropical. Marrocos (?)

No Brasil; Alagoas, Sergipe, Rio de Janeiro, São Paulo, Paraná.

Discussão - Nephtys squamosa aproxima-se de Nephtys serratifolia Ehlers, 1897, que também apresenta lamelas dorsais imbricadas à maneira de escamas, estando porém restrita ao extremo austral da América do Sul. Nephtys acrochaeta, também referida para fundos de plataforma da costa sudeste do Brasil, apresenta lamelas dorsais menos desenvolvidas e setas pós-aciculares com esporão característico. Os exemplares de Nephtys squamosa provenientes da costa paranaense diferem ligeiramente, em relação às características das lamelas parapodiais, dos exemplares descritos por Nonato \& Luna (1970) para o nordeste do Brasil. 
Nephtys fluviatilis Monro, 1937: 246, fig. 2 a-c; Orensanz \& Estivariz, 1971: 101, figs 23-31; Orensanz \& Gianuca, 1974: 10.

Descrição - 20 exemplares examinados, atingindo até $35 \mathrm{~mm}$ de comprimento e $2,3 \mathrm{~mm}$ de largura (sem contar os parapódios), para cerca de 60 setígeros. Coloração fortemente amarelada, com faixas longitudinais descont ínuas de pigmentação parda na região dorso-anterior do corpo. Em exemplares fixados, as zonas de pigmentação anteriores se mantêm um pouco esmaecidas e com aspecto tipicamente estriado e descont ínuo nas áreas dorso-laterais. Em fêmeas maduras, as bases para podiais se apresentam infladas e pardo-violáceas, por transparência, em virtude do acúmulo de óvulos. Prostômio de formato trapezoidal, quatro vezes mais estreito que a largura máxima do corpo, com um par de ocelos negros puntiformes, dorsolaterais, um par de antenas frontais e um par de antenas ventrais, mais largas e dirigidas lateralmente. Brânquias aparentes a partir do set ígero $5 \mathrm{e}$ bem desenvolvidas até o set ígero 36, quando desaparecem bruscamente; apresentam próximo à sua base um pequeno lobo, cônico e achatado, mais desenvolvido em segmentos medianos (Fig. 6).

Lamelas pré-setais de setígeros anteriores rudimentares. Lamelas pós-setais dos notopódios pouco desenvolvidas em segmentos anteriores e arredondadas em segmentos medianos. Lamelas pós-setais dos neuropódios bem desenvolvidas, com extremidade foliácea em segmentos anteriores e medianos (Fig. 7). Cirros ventrais curtos e cônicos em segmentos anteriores e medianos, vestigiais nos posteriores. Em parapódios posteriores, as lamelas e cirros se tornam mais curtos que os lobos set ígeros ou aciculares. Parapódios e brânquias com cecos internos, visíveis por transparência. Setas pré-aciculares curtas e barradas. Setas pós-aciculares muito longas, achatadas, com fileiras transversais de dentículos na porção basal. Pigídio arredondado, com cirro mediano-ventral alongado. Probóscide com 20 pares de papilas bífidas terminais. Parte distal da probóscide com 20-21 fileiras de papilas, progressivamente mais curtas em direção basal e acompanhadas por uma grande papila medial ventral.

Ocorrência - Est. MG-1 (MCBM-BPO-13, 2 exs); Est. PR-1 (MCBM-BPO-14, 4 exs); Est. GR-2 (MCBM-BPO-15, 6 exs); Est. MG-3 (MCBM-BPO-16, 8 exs). No interior das baías de Paranaguá e Guaratuba, em bancos lodosos próximos a manguezais e em gamboas (rios de maré) expostas a água praticamente doce durante as vazantes, em pequenas profundidades.

Distribuição - Desde a Argentina (mar Chiquita) até o Paraná.

Discussão - Nephtys fluviatilis, descrita para o Uruguai (Monro, 1937), é espécie freqüente em ambientes estuarinos do Rio Grande do Sul até o norte da Argentina. $\mathrm{O}$ presente registro amplia grandemente sua área de distribuição para o norte. Os ex emplares paranaenses diferem ligeiramente dos exemplares mais austrais em relação ao aparecimento e término das brânquias. A espécie pode ser facilmente diagnosticada pelo seu padrão de coloração e por estar restrita a ambientes de baixa salinidade. 
Nephtys magellanica Hartman, 1938: 146, fig. 62; Hartman, 1940: 248, est. 41, figs. 100-103; Hartman, 1950: 100.

Nephtys simoni Perkins, 1980: 37, figs 15-16.

Descrição - 10 exemplares examinados, com o maior atingindo $27 \mathrm{~mm}$ de comprimento e 1,2 mm de largura, para cerca de 100 set ígeros. Corpo amarelado no álcool, com prostômio dotado de mancha avermelhada, puntiforme e mediana. Margem anterior do prostômio convexa e espatulada. Largura máxima do prostômio de 1/4 a 1/5 da largura máxima do corpo. Antenas laterais com inserção ventro-lateral, aproximadamente do mesmo tamanho que as antenas frontais. Brânquias visíveis a partir do setígero 3, não ocupando mais de $1 / 3$ da distância entre os ramos parapodiais, quando distendidos. Cirros dorsais curtos e digitados. Lobos neuropodiais pós-setais muito desenvolvidos na região anterior (Fig. 8), decrescendo gradualmente em direção ao extremo posterior do corpo (Fig. 9). Cirros ventrais proporcionalmente maiores em parapódios posteriores. Setas pré-aciculares curtas e barradas. Setas pós-aciculares em fita, com até 4 vezes o comprimento dos ramos parapodiais; setas centrais com área proximal denteada, em séries transversais que diminuem de número distalmente e setas dorsais lisas ou tenuemente serrilhadas. Probóscide com 11 pares de papilas bífidas terminais e 22 fileiras longitudinais sub-distais, com 4-9 papilas cada uma. Par interno de mandíbulas fortemente achatado, com formato triangular.

Ocorrência - Est. A-5 (MCBM-BPO-17, 1 ex.); Est. D-7 (MCBM-BPO-18, 1 ex.); Est. D-8 (MCBM-BPO-19, lex.); Es. PS-1 (MCBM-BPO-20, 1 ex.); Est. PS-2 (MCBMBPO-21, 5 exs); Est. 6122 (MCBM-BPO-22, 1 ex.). Em fundos de areia fina e areia média, na entrada das baías e na plataforma continental, desde a região entre-marés até 47 metros de profundidade.

Distribuição - Costa leste norte-americana; costa pacífica americana, da Califórnia ao Peru; costa sudeste do Brasil.

Discussão - A distinção entre Nephtys simoni e N. magellanica Augener, 1912 parece problemática. Segundo Perkins (1980), as duas espécies difeririam pelas características do prostômio e pelo maior ou menos desenvolvimento das brânquias. Decido seguir a orientação deste autor e considerar $N$. magellanica como espécie restrita ao extremo meridional do continente sul-americano. Exemplares referidos a esta última, provenientes de Ubatuba (Fauchald, 1976; Amaral, 1977; Lana, 1981) são aparentemente idênticos a Nephtys simoni.

Inermonephtys Fauchald, 1968

Inermonephtys palpata Paxton, 1974

(Figs. 10-15) 
Inermonephtys palpata Paxton, 1974: 200, figs. 2-6; Rainer \& Hutchings, 1977: 320 .

Descrição - 4 exemplares examinados; descrição baseada em um fragmento anterior com 53 setígeros, $22 \mathrm{~mm}$ de comprimento e $1,5 \mathrm{~mm}$ de largura máxima, sem contar os parapódios. Coloração âmbar amarelada, no álcool. Prostômio alongado e relativamente estreito (1/5 da largura máxima do corpo), sem manchas ocelares e provido de um par de antenas anteriores bífidas com inserção subdistal (Fig. 10). Örgãos nucais cônicos e muito pequenos, situados na porção postero-dorsal do prostômio. Brânquias já aparentes no setígero 3 , presentes até os últimos segmentos do fragmento examinado, acompanhadas por cirros notopodiais cônicos nos segmentos anteriores e longos e cirriformes em segmentos medianos (Fig. 12) e posteriores (Fig. 14). As brânquias, sempre involutas, chegam a ocupar $2 / 3$ do espaço interramal quando melhor desenvolvidas, apresentando uma pequena bossa ou corcova junto à sua base, próximo ao ponto de inserção do cirro notopodial (Fig. 12). Lamelas pré-setais notopodiais sempre curtas e arredondadas, menos desenvolvidas que os lobos set ígeros; lamelas pós-setais notopodiais mais longas, volumosas e arredondadas na porção anterior do corpo (Fig. 11) e lanceoladas em segmentos medianos e posteriores (Fig. 14). Lamelas ou expansões dorsais inteiramente ausentes. Lamelas neuropodiais muito curtas e arredondadas em segmentos anteriores; as pós-setais se tornam acuminadas em segmentos posteriores (Figs. 1314). Cirros ventrais extremamente desenvolvidos e sempre maiores que as demais lamelas neuropodiais (Figs. 11-12); tornam-se progressivamente menores em direção à região posterior do corpo. Em virtude de sua inserção, podem ser confundidos, em alguns pontos do corpo, com uma lamela pós-setal. Setas dorsais da região anterior muito longas e recurvadas, decrescendo progressivamente de tamanho no sentido posterior. Setas pré-aciculares capilares barradas em maior ou menor grau, alongadas, com anelações indistintas (Fig. 15a). Setas pós-aciculares de dois tipos: a) furcadas ou liriformes, com os ramos de comprimento equivalente (Fig. 15b); b) muito longas, farpadas ao longo de toda a sua extensão (Fig. 15c). Probóscide curta e desprovida de quaisquer tipos de papilas terminais ou sub-terminais. Mandíbulas amareladas, translúcidas e fortemente achatadas.

Ocorrência - Est. 6256 (MCBM-BPO-23, 1 ex.); Est. 6138 (MCBM-BPO-24, 2 exs): Est. 6287 (MCBM-BPO-25, 1 ex.). Em fundos areno-lodosos e arenosos da plataforma, entre 25 e 88 metros de profundidade.

Distribuição - Queensland (Austrália); costa sudeste do Brasil (São Paulo, Paraná).

Discussão - O gênero Inermonephtys foi criado por Fauchald (1968) para abrigar os Nephtyidae com probóscide desprovida de papilas e sem o par de antenas frontais. Três espécies são conhecidas para o gênero: Inermonephtys gallardi Fauchald. 1968, do Vietnam, Inermonephtys inermis (Ehlers, 1887), com ampla distribuição tropical e sub-tropical e Inermonephtys palpata Paxton, 1974, da Austrália. I. palpata difere das duas outras por apresentar antenas laterais bífidas (à semelhança de palpos frontais) e setas pré-aciculares barradas serrilhadas. E particularmente signi- 
ficativa a ocorrência da espécie, antes referida apenas na região entre-marés de praias australianas, em fundos de plataforma do Atlântico Sul.

\author{
Aglaophamus Kinberg, 1866 \\ Aglaophamus juvenalis (Kinberg, 1866)
}

(Figs. 16-17)

Aglaopheme juvenalis Kinberg, 1866: 240.

Aglaophamus juvenalis Hartman, 1949: 51, est. 7, fig. 1;Fauchald, 1976: 16,

fig. 1 a-c.

Aglaophamus dibranchis Temperini, 1981: 26, fig. 61.

Descrição - 9 exemplares examinados; a descrição se baseia num indivíduo completo com $30 \mathrm{~mm}$ de comprimento para 60 setígeros e em um fragmento anterior com $28 \mathrm{~mm}$ de comprimento para 51 setígeros. Coloração âmbar amarelada no álcool, com setas muito escuras. Prostômio translúcido, sem manchas ocelares ou pigmentação evidentes. Brânquias presentes a partir do setígero 4 , conspícuas até aproximadamente o set ígero 45. Lamelas notopodiais pouco desenvolvidas nos segmentos anteriores (Fig. 16); lamelas pós-setais inicialment arredondadas, tornando-se mais desenvolvidas e foliáceas na região mediana do corpo e diminuindo progressivamente de tamanho na região posterior. Lamelas neuropodiais arredondadas e foliáceas, com as pós-setais sempre mais desenvolvidas. Cirros notopodiais curtos e arredondados nos segmentos anteriores (Fig. 16), tornando-se muito longos e filiformes nos segmentos medianos (Fig. 17) e vestigiais na região posterior do corpo. Brânquias e cirros notopodiais fortemente papilados. A partir dos setígeros 8-9 e até as proximidades do set ígero 25 , evidencia-se um lobo digitado e ereto na margem superior dos neuropódios (Figs. 16-17). Setas pré-aciculares barradas, com extremidade muito fina e ondulada. Setas pós-aciculares de dois tipos: a) longas e lanceoladas, com bordo liso; b) furcadas muito curtas, com bordos internos serrilhados. Probóscide com 20 papilas bífidas terminais e uma grande papila medial dorsal. 16 fileiras de papilas sub-terminais, com 4-5 papilas por fileira. Superfície proximal da probóscide lisa.

Ocorrência - Est. F-3 (MCBM-BPO-26, 1 ex.); Est. F-9 (MCBM-BPO-27, 2 exs); Est. 6244 (MCBM-BPO-28, 1 ex.); Est. 6254 (MCBM-BPO-29, 4 exs); Est. 6255 (MCBMBPO-30, 1 ex.); Est. 6094 (MCBM-BPO-31, 1 ex.).

Distribuição - Costa sudeste do Brasil (RJ, SP, PR).

Discussão - Os presentes registros ampliam para o sul a área de distribuição da espécie, descrita para o Rio de Janeiro (Kinberg, 1866) e reencontrada posteriormente na região de Ubatuba (Fauchald, 1976). Aglaophamus juvenalis diferencia-se das espécies congêneres por apresentar 16 fileiras de papilas sub-terminais, número aberrante para a fam ília como um todo. Fauchald (1976) discutiu as afinidades existentes entre $A$. juvenalis e $A$. tabogensis Monro, 1933, espécie muito parecida, descrita 
para a costa pacífica do Panamá. Os exemplares examinados no presente levanta. mento diferem daqueles descritos para Ubatuba em relação ao aparecimento e redução dos lobos digitados na margem superior dos neuropódios. Esta diferença é aqui considerada de natureza intra-específica. Exemplares provenientes da plataforma sudeste do Brasil e identificados como Aglaophamus dibranchis (Grube, 1877) por Temperini (1981) são aqui referidos a $A$. juvenalis. A. dibranchis é espécie aparentemente restrita ao Indo-Pac ífico.

\section{Aglaophamus uruguayi Hartman, 1953}

(Figs. 18-19)

Aglaophamus uruguayi Hartman, 1953: 32, fig. 8 a-d

Descrição - 7 exemplares examinados; descrição baseada num indivíduo completo, com 55 set ígeros, $20 \mathrm{~mm}$ de comprimento e $1,3 \mathrm{~mm}$ de largura e num fragmento anterior com 48 set ígeros, $15 \mathrm{~mm}$ de comprimento e $1,2 \mathrm{~mm}$ de largura. Coloração de esbranquiçada a avermelhada, em material fixado. Prostômio espatulado, com um par de antenas frontais, um par de antenas ventrais mais longas e um par de manchas ocelares puntiformes na metade postero-dorsal. Brânquias presentes a partir do setígero 4 , ainda vestigiais; são bem desenvolvidas a partir dos setígeros 9-10, estendendo-se até aproximadamente o set ígero 40. Ramos parapodiais pequenos e muito separados uns dos outros na região anterior do corpo (Fig. 18). Lamelas pré e pós-setais pouco desenvolvidas ao longo de todo o corpo (Figs. 18-19). As bordas superiores dos neuropódios apresentam lobos eretos do setígero 15 a 40 (Fig. 19). Estes lobos apresentam-se cirriformes e muito longos na região mediana do corpo, ultrapassando em comprimento as próprias brânquias; ambos são profusamente fimbriados. Cirros notopodiais sempre curtos, cônicos e foliáceos; cirros ventrais mais longos nos segmentos anteriores, progressivamente mais curtos nos posteriores. Acículos robustos e fortemente recurvados nas extremidades. Setas pré-aciculares curtas e barradas. Setas pós-aciculares de dois tipos: a) longas e lisas; b) furcadas mais curtas, com os dois ramos serrilhados e de comprimento equivalente. Probóscide com 20 papilas bífidas terminais e 20 fileiras longitudinais, irregulares. de 6-9 papilas sub-terminais, mais curtas no lado dorsal.

Ocorrência - Est. 6254 (MCBM-BPO-32, 4 exs); Est. 6088 (MCBM-BPO-33, 1 ex.); Est. 6138 (MCBM-BPO-34, 2 exs). Em fundos lodosos e areno-lodosos da plataforma, entre 60 e 95 metros.

Distribuição - Costa sul e sudeste do Brasil (RS, SC, PR, SP).

Discussão - A espécie era conhecida apenas da descrição original, baseada em material presumidamente da costa uruguaia (Hartman, 1950). Como dito anteriormente, as coordenadas referidas correspondem a fundos de plataforma da costa do Rio Grande do Sul.

Aglaophamus uruguayi difere de $A$. juvenalis em relação ao número de papilas da probóscide, por apresentar brânquias muito reduzidas nos primeiros setígeros $\mathrm{e}$ pelo menor desenvolvimento dos cirros notopodiais em parapódios medianos. 


\section{COMENTÁRIOS SOBRE A DISTRIBUIÇÃO GEOGRÁFICA DAS ESPÉCIES AO LONGO DO LITORAL PARANAENSE E PLATAFORMA CONTINENTAL ADJACENTE}

O litoral paranaense é formado por linhas de praias oceânicas, interrompidas pelas baías de Paranaguá, ao norte, e Guaratuba, ao sul. As praias de mar aberto são de areias finas bem selecionadas, semelhantes às do setor interno da plataforma. A natureza do sedimento de fundo da Baía de Paranaguá foi estudada por Bigarella (1978). As áreas centrais e internas são tipicamente ambientes de baixa energia, com capeamento detrítico terrígeno misturado com material biogênico de origem local. Próximo às barras de acesso, sujeitas à ação mais intensa de ondas, os fundos são constituídos por areias finas, semelhantes às das praias oceânicas e setor interno da plataforma adjacentes. As características texturais dos fundos da Baía de Guaratuba são reflexo de regimes de transporte semelhantes aos que prevalecem na Baía de Paranaguá. Ambas as baías apresentam-se margeadas por manguezais e recortadas por rios de maré ou gamboas.

Ao largo da costa paranaense, a plataforma continental apresenta-se dividida em três setores. 0 setor interno, que vai da linha de costa até 45-50 metros de profundidade, está constituído por areias finas bem selecionadas, retrabalhadas em ambientes de alta energia (Bigarella, 1978). A plataforma média é representada por uma fácies lamosa, por vezes descont ínua, que se estende até os 100-120 metros de profundidade. A plataforma externa, que se prolonga até o talude, é constituída por sedimentos carbonáticos biogênicos, envolvendo restos de moluscos, briozoários e corais, misturados a uma fração lodo-arenosa mais ou menos desenvolvida.

A Figura 20 apresenta os registros de ocorrência dos Nephtyidae ao longo do litoral paranaense e na plataforma continental adjacente. As densidades populacionais das espécies registradas no litoral paranaense são, em geral, baixas. Foram observadas populações mais numerosas de Nephtys fluviatilis $\left(8 \mathrm{inds} / 0,05 \mathrm{~m}^{2}\right.$, Est. MG-3, 30/01/1984), Nephtys simoni (12 juvenis/0,05 m², Est. 6139, 21/08/1982) e Aglaophamus uruguayi (4 inds $/ 0,05 \mathrm{~m}^{2}$, Est. $\left.6254,20 / 05 / 1983\right)$. Nephtys fluviatilis, $N$. squamosa, N. simoni e Aglaophamus juvenalis ocorrem no interior das baías. Nephtys fluviatilis é, no entanto, a única espécie exclusiva de ambientes estuarinos; nas gamboas ou rios de maré e nos manguezais, populações densas podem se desenvolver em locais cobertos por água praticamente doce durante as vazantes. As demais espécies capazes de penetrar nos estuários restringem-se, no entanto, a fundos próximos das barras de acesso das baías, em áreas com salinidade média não inferior a 25\%. Nephtys squamosa e $N$. simoni ocorrem ainda em fundos de areia fina bem selecionada, nas praias de mar aberto e no setor interno da plataforma. Embora habitem ambientes similares, as áreas de distribuição destas espécies tendem a não se superpor; foram registradas juntas em uma única estação de plataforma (Est. 6124, areia fina, 39 metros, dragagem). Aglaophamus juvenalis ocorre em fundos arenosos com componente siltico-argiloso mais desenvolvido, particularmente na zona de transição entre os setores interno e médio da plataforma. Aglaophamus uruguayi tem padrão de distribuição bem definido; ocorre em fundos silticoargilosos do setor médio da plataforma, entre 60 e 95 metros de profundidade. Nephtysacrochaeta e Inermonephtys palpata foram também registradas em profun- 
didades semelhantes, mas já em fundos siltico-argilosos com fração bem desenvolvida de cascalho calcário. $N$. acrochaeta foi referida também para fundos lodosos de plataforma, em profundidades menores (4-10 metros), nas áreas de Ubatuba e Cananéia (SP), por Fauchald (1976). O registro original da espécie (Hartman. 1950) é igualmente de fundo lodoso, a 80 metros de profundidade, ao largo da costa do Rio Grande do Sul. I. palpata foi registrada uma única vez em fundos de areia fina do setor interno da plataforma (Est. 6256, 25 metros).

Não houve registro de nenhuma espécie de Nephtyidae abaixo dos 100 metros de profundidade. Embora o esforço de coleta tenha sido concentrado nos setores rasos de plataforma, é possível que as espécies da fam ília sejam efetivamente raras ou mesmo ausentes nos fundos carbonáticos do setor externo. próximo ao talude continental.

\section{RESUMO}

Os Nephtyidae do litoral do Estado do Paraná estão representados por 7 espécies: Neptys acrochaeta, N. squamosa, N. fluviatilis, N. simoni, Inermonephtys palpata, Aglaophamus juvenalis e A. uruguayi. Inermoneptys palpata, conherida anteriormente da Austrália, é ocorrência nova em águas atlânticas. Nephtys simoni é também ocorrência nova para a costa brasileira. Descriçóes e comentários solure' a distribuição geográfica são fornecidos para todas as espécies, juntamente com uma chave de identificação.

\section{AGRADECIMENTOS}

A Ana Cláudia Muller e Iago Ferreira Leite, pela coleta de parte do material. A Iara Teix eira, pela preparação dos desenhos. Ā Comissão Interministerial para o. Recursos do Mar e ao Conselho Nacional de Desenvolvimento Cient ífico e Tecnológico, pelo financiamento de parte do trabalho. Á Diretoria de Hidrografia c Navegação, por tornar disponível o material de plataforma (Operações Sueste I e II). Ao Dr. Edmundo Nonato, pelas sugestões e pelas facilidades em relação à literatura.

\section{REFERÊNCIAS BIBLIOGRĀFICAS}

AMARAL, A. C. Z. (1977) Anelídeos poliquetos do inf ralitoral em duas enseadas da região de Ubatuba: aspectos ecológicos. Tese de Doutorado, Instituto Occanográfico, Universidade de São Paulo, 137 pp.

AUGENER, H. (1912) Beitrag zur Kenntnis verschiedener Anneliden und Bemerkungen uber die nordischen Nephtys-arten und deren epitoke Formen. Arch. Naturgesch. Berlin $78 \mathrm{~A}$ (10): 162-212.

BIGARELlA, J. J. (1978) A Serra do Mar e a porção oriental do Estado do Paraná. Governo do Paraná-Secretaria de Estado de Planej amento/ ADEA, 249 pp.

EHLERS, E. (1887) Report on the annelids of the dredging expedition of the U. S. Coast Survey Steamer "Blake". Mem. Mus. comp. Zool. Harvard 15: VI + 335 pp.

- (1897) Polychaeten. In: Ergebnisse der Hamburguer Magalhaensischen sammelreise 1892$1893,3: 148 \mathrm{pp}$.

FABRICIUS, O. (1780) Fauna Groenlandica ... etc, XVI + 452 pp. Hafniae et Lipsiae.

FAUCH ALD, K. (1968) Nephtyidae (Polychaeta) from the Bay of Nha Trang, South Viet Nam. NAGA Report 4 (3):1-33.

- (1976) Some Nephtyidae (Polychaeta) from Ubatuba, Brazil. Bull. So. Calif. Acad. Sc. 75 (1):16-19. 
GRUBE, A. E. (1877) Anneliden-Ausbeute S. M. S. Gazelle. Monatsb. Akad. Wiss. Berl., vol. 1877: 509-554. (impresso em 1878)

- (1881) Beschreibungen von neuen Anneliden des zoologischen Museums zu Berlin. SitzBer. naturf. Gesells. Leipzig, pp. 109-117.

HARTMAN, O. (1940) Polychaetous annelids. Chrysopetalidae to Goniadidae. All. Hanc. Pacif. Exp. $7(1 / 2): 171$ pp.

- (1949) The marine annelids erected by Kinberg with notes on some other types in the Swedish Museum. Arkiv for Zoologi 42A (1): 1-137.

- (1950) Polychae tous annelids. Goniadidae, Glyceridae and Nephtyidae. All. Hanc. Pacif. Exp. 15:181 pp.

- (1953) Non-pelagic Polychaeta of the Swedish Antarctic Expedition 1901-1903. Further Zoological Results of the Swedish Antarctic Expedition 1901-1903, vol. 4(11):83 pp.

KINBERG, J. G. H. (1866) Annulata nova Ófv. Svenska Vetensk. Akad. F•o rh. 22:239-258.

LANA, P. C. (1981) Padrões de distribuição e diversidade específica de anelídeos poliquetos na região de Ubatuba, Estado de São Paulo. Dissertação de Mestrado, Instituto Oceanográfico, Universidade de São Paulo, $111 \mathrm{pp}$.

MONRO, C. C. A. (1933) The Polychaeta Errantia collected by Dr. C. Crossland at Colon in the Panama region and the Galapagos Islands during the expedition of the S. Y. "St. George". Proc. Zool. Soc. London 1933 (1):1-96.

- (1937) On some freshwater polychaetes from Uruguay. Ann. Mag. Nat. Hist. 10 (20): 241250.

NONATO, E. F. (1981) Contribuição ao conhecimento dos anel ídeos poliquetas bentônicos da plataforma continental brasileira, entre Cabo Frio e o Arroio Chuí. Tese de Livre Docência, Instituto Oceanográfico, Universidade de São Paulo, $246 \mathrm{pp}$.

NONATO, E. F. \& LUNA, J. A. (1970) Anelídeos poliquetas do nordeste do Brasil. I. Poliquetas bentônicos da costa de Alagoas e Sergipe. Bolm Inst. oceanogr., S. Paulo, 19:57-130.

ORENSANZ, J. M. \& ESTIVAP.IZ, M. C. (1971) Los anelidos poliquetos de aguas salobres de la Provincia de Buenos Aires. Rev. Mus. La Plata 11 (98):96-114.

ORENSANZ, J. M. \& GIANUCA, N. M. (1974) Contribuição ao conhecimento dos anelídeos poliquetas do Rio Grande do Sul. I. Lista sistemática preliminar e descrição de três novas espécies. Comun. Mus. Ci. PUC-RS 4: 1-37.

PAXTON, H. (1974) Contribution to the study of Australian Nephtyidae. Rec. Aust. Mus. 29 (7):197-208.

PERKINS, T. H. (1980) Review of species previously referred to Ceratonereis mirabilis and descriptions of new species of Ceratonereis, Nephtys and Goniada. Proc. Biol. Soc. Wash. 93 (4): $1-49$.

RAINER, S. \& HUTCHINGS, P. (1977) Nephtyidae (Polychaeta: Errantia) from Australia. Rec. Aust. Mus. 31 (8):307-347.

RULLIER, F. \& AMOUREUX, L. (1979) Annélides polychètes. Campagne de la Calypso au large des côtes atlantiques de l'Amérique du Sud (1961-1962). Ann. Inst. Océanogr. 55, fasc. supl.: 145-206.

SAVIGNY, J. C. (1818) Les annèlides, In: "Histoire naturelle des animaux sans vertébres", J. B. de Lamarch. Paris 5:274-374.

SCHMARDA, L. K. (1861) Neue wirbellose Thire beobachtet und gesammelt auf einer Reise um die Erde, 1853 bis 1857, volume 1: Neue Turbellarien, Rotatorien und Anneliden. Part. 2, pp. 1-164. Leipzig, Wilhelm Engelmann.

TEMPERINI, M. T. (1981) Sistemática e distribuição dos poliquetos errantes da plataforma continental entre as latitudes de $23^{\circ} 05^{\prime} \mathrm{S}$ e $30^{\circ} 00^{\prime} \mathrm{S}$. Dissertação de Mestrado, Instituto Oceanográfico, Universidade de São Paulo, 89 pp. 

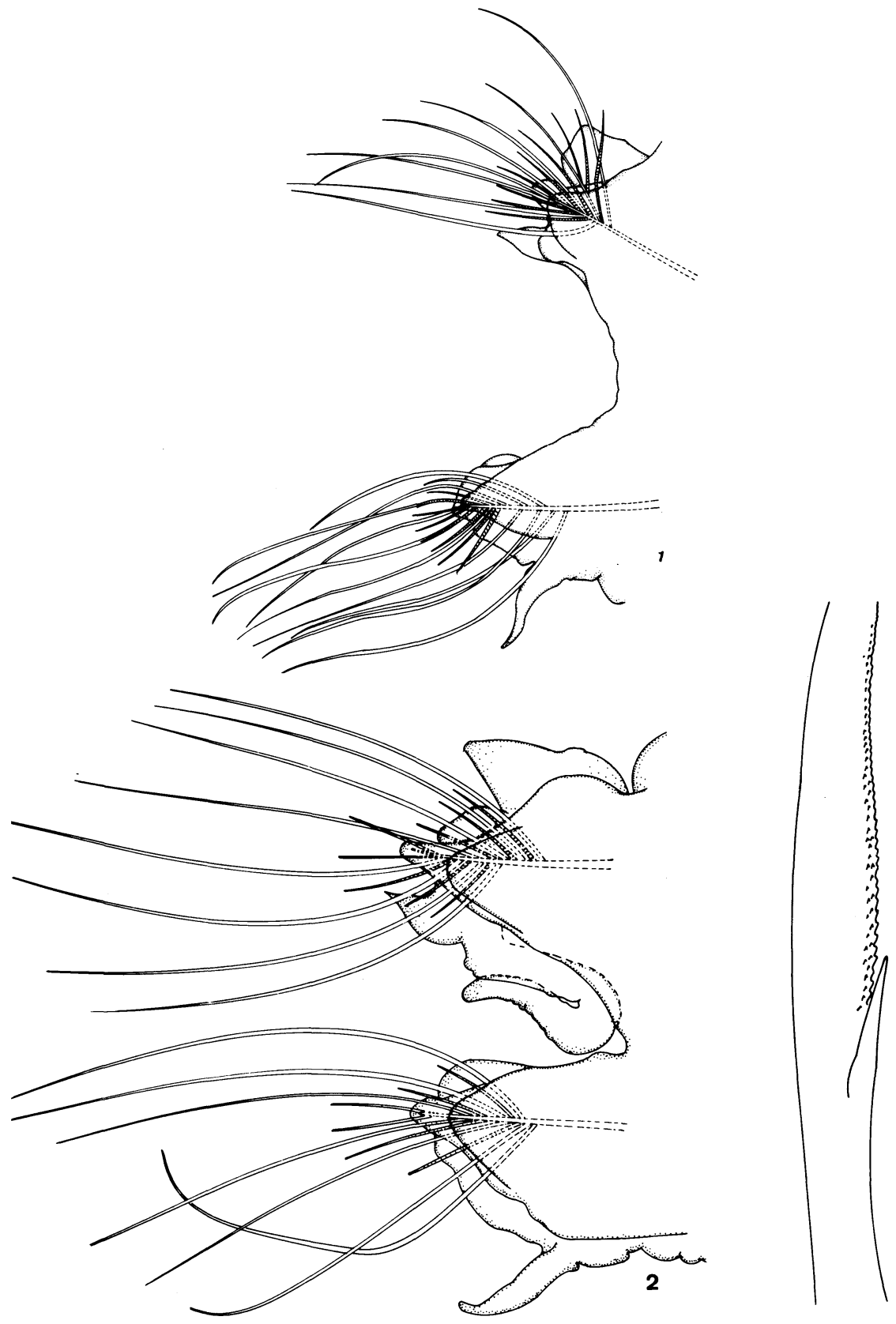

3

\section{Nephtys acrochaeta}

Fig. 1 - Parapódio do setígero 10, em vista anterior

Fig, 2 - Parapódio do set ígero 20, em vista anterior

Fig. 3 - Neuroseta pós-acicular, com esporão basal 

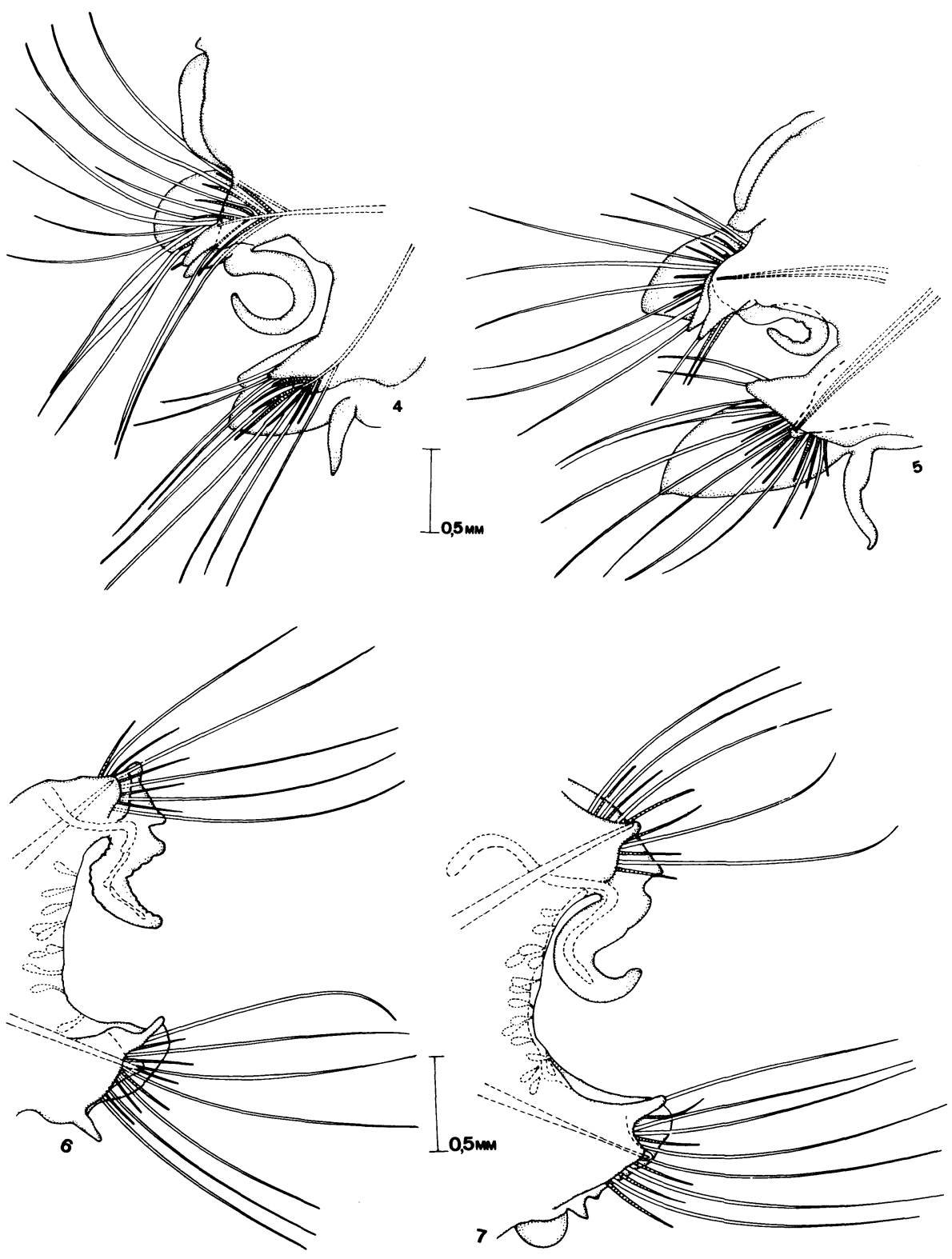

Nephtys squamosa

Fig. 4 - Parapódio do setígero 10, em vista anterior Fig. 5 - Parapódio do set ígero 20, em vista anterior Nephtys fluviatilis

Fig. 6 - Parapódio do set ígero 10, em vista anterior Fig. 7 - Parapódio do set ́́gero 20, em vista anterior 

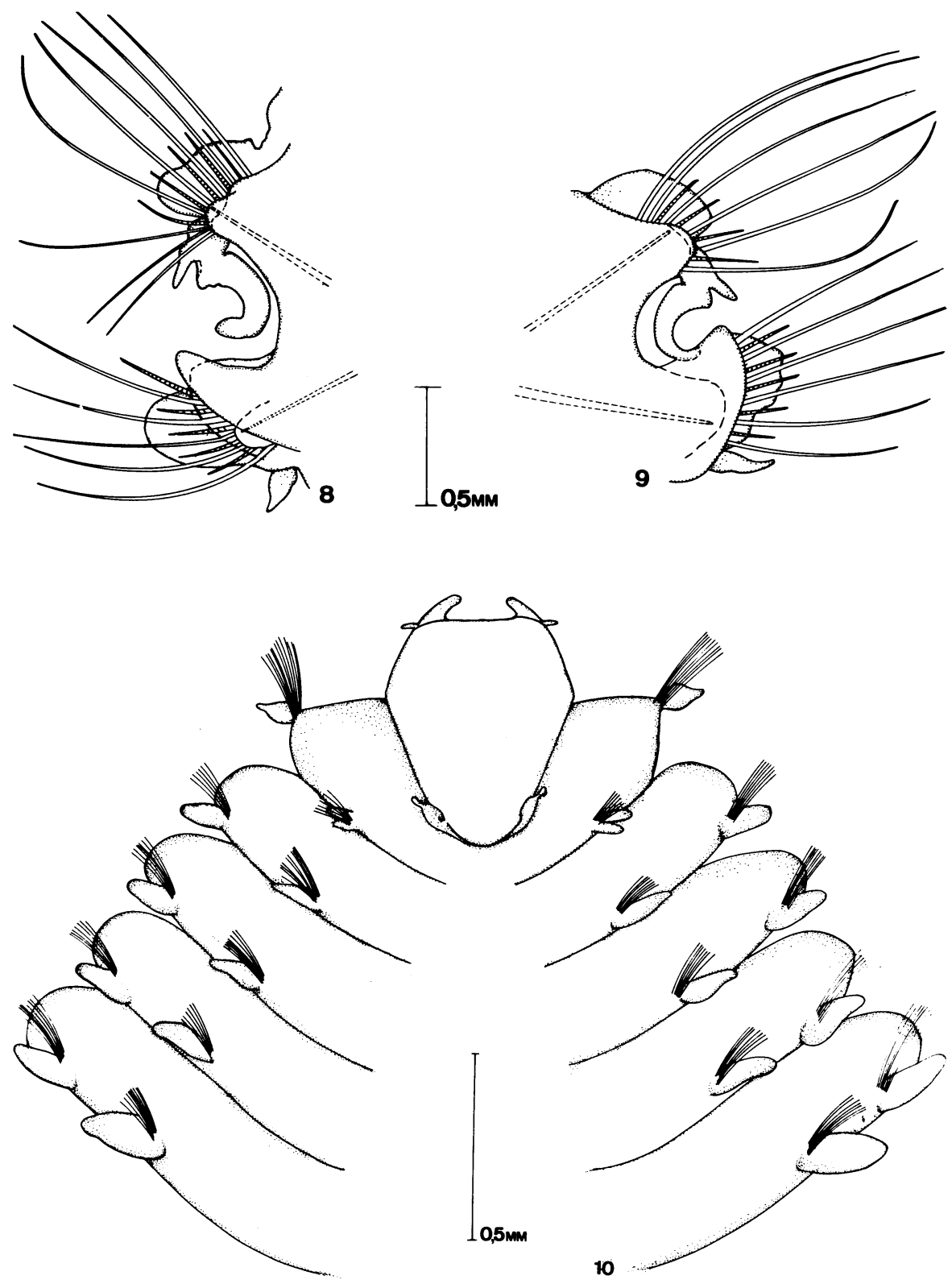

Nephtys simoni

Fig. 8 -Parapódio do setígero 10 , em vista anterior

Fig. 9 - Parapódio do setígero 20, em vista anterior

Inermonephtys palpata

Fig. 10 - Região anterior, em vista dorsal 

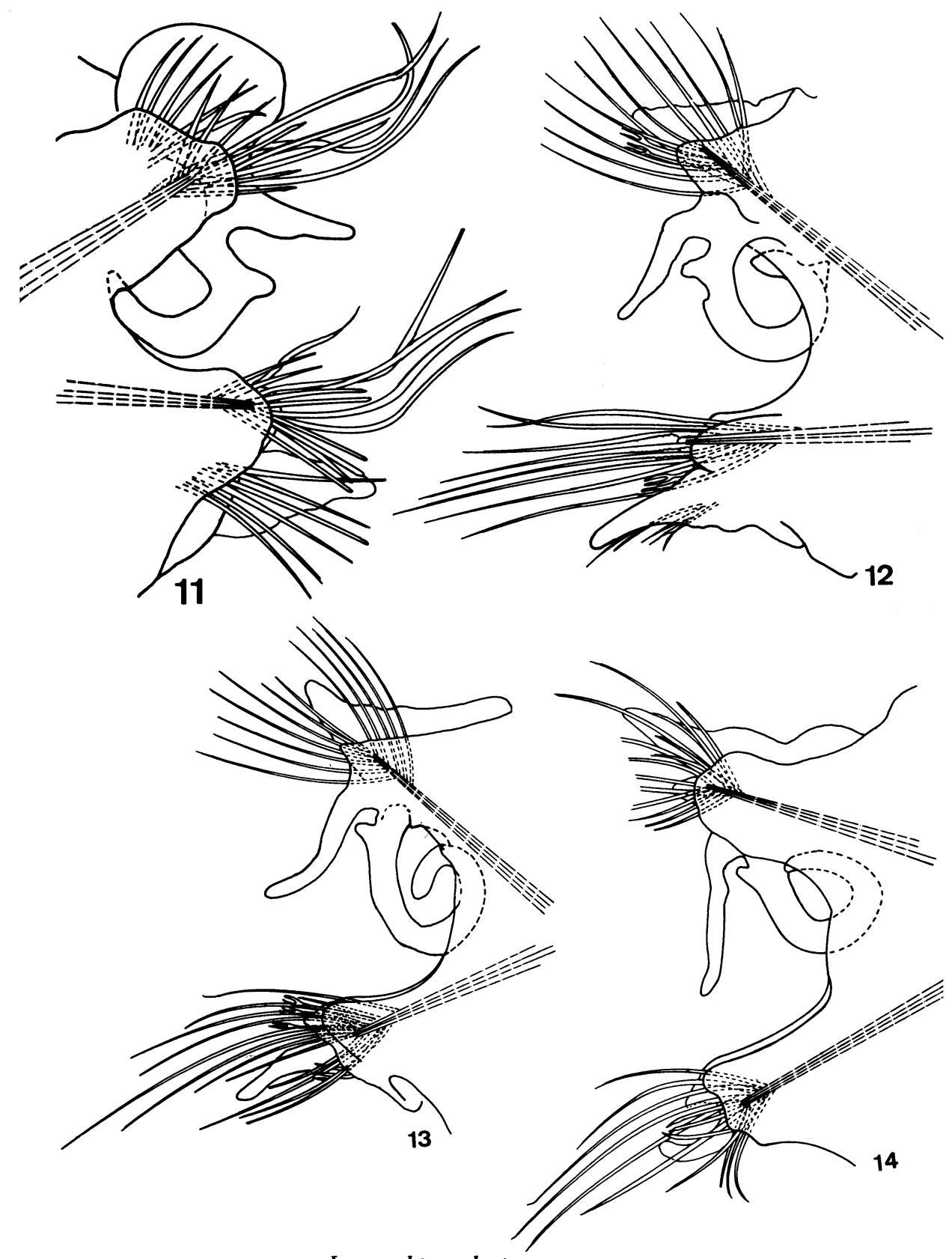

Inermophtys palpata

Fig. 11 - Parapódio do setígero 10

Fig. 12 - Parapódio do setígero 20

Fig. 13 - Parapódio do setígero 30

Fig. 14 - Parapódio do setígero 40 

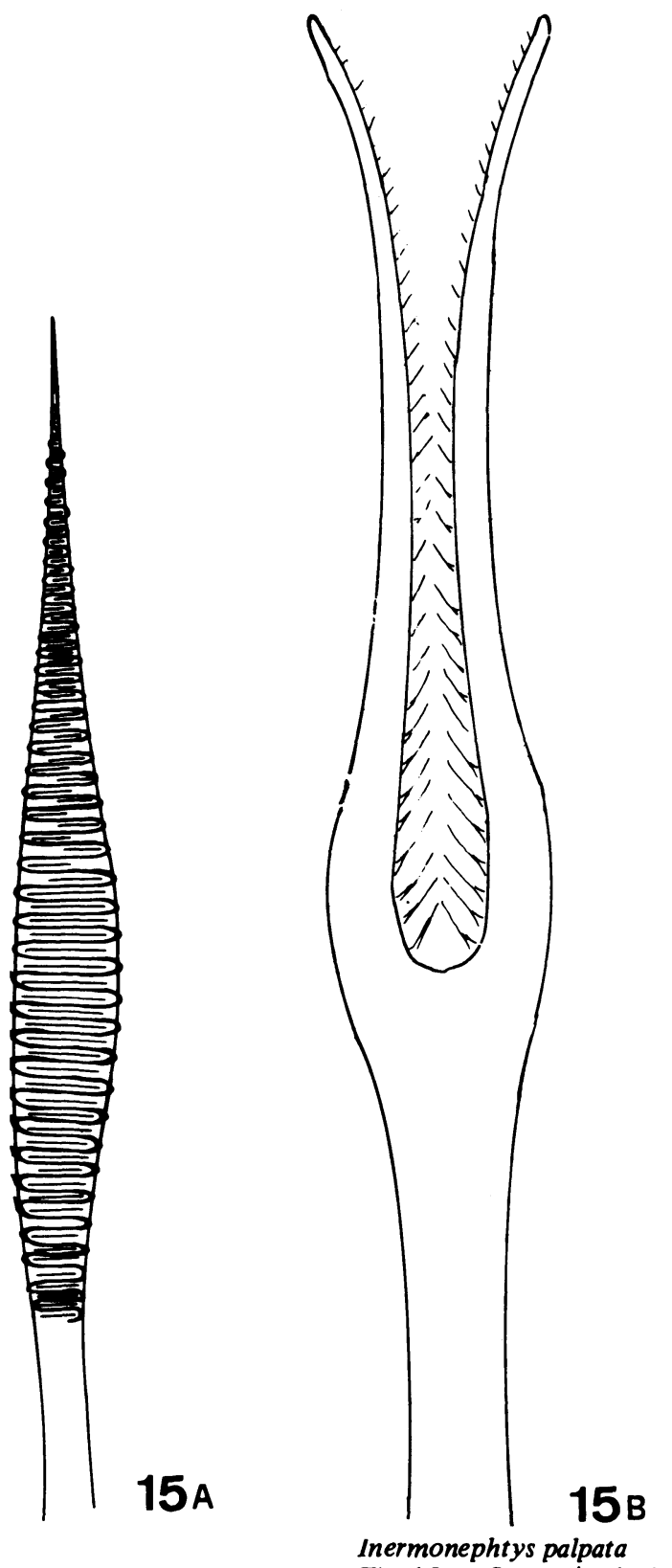

Fig. 15a - Seta pré-acicular barrada

Fig. $15 \mathrm{~b}$ - Seta pós-acicular furcada

Fig. 15c - Seta pós-acicular alongada 


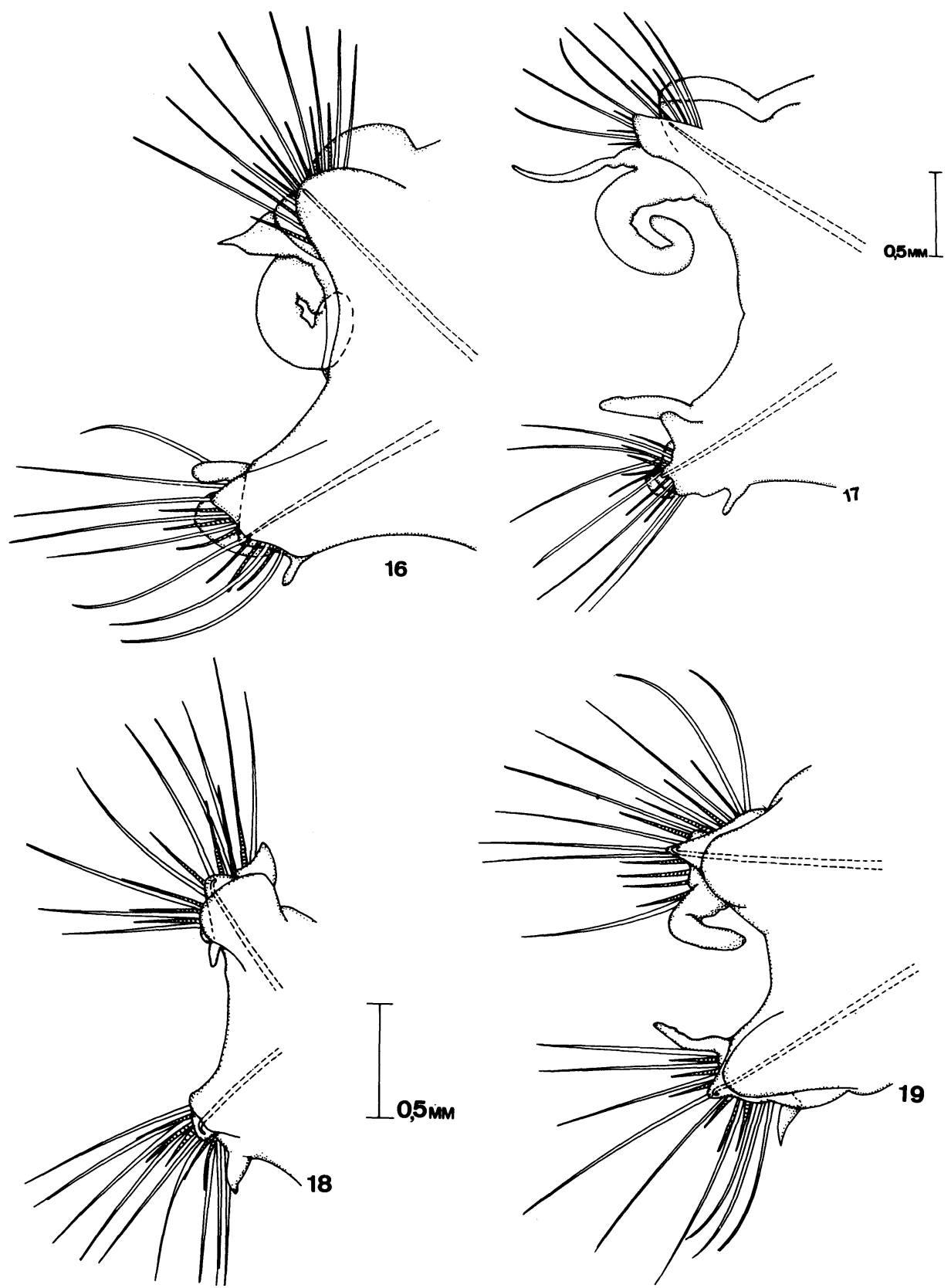

Aglaophamus juvenalis

Fig. 16 - Parapódio do setígero 10

Fig. 17 - Parapódio do setígero 20

Aglaophamus uruguayi

Fig. 18 - Parapódio do set ígero 10

Fig. 19 - Parapódio do set ígero 20 


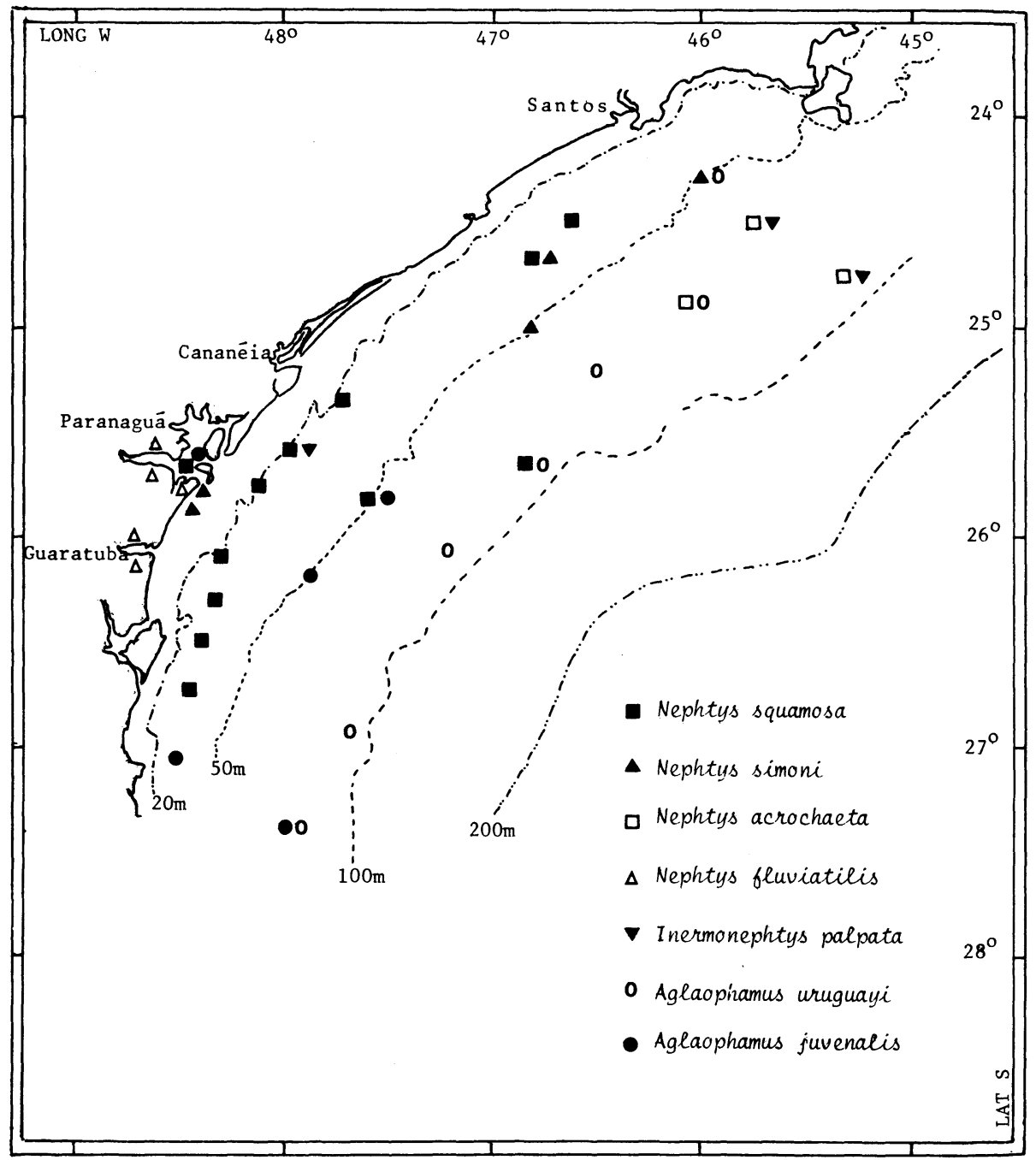

Fig. 20 - Distribuição das espécies de Nephtyidae ao largo do litoral paranaense e na plataforma continental adjacente. 